\section{Response to: 'Concerns about the operational definition of remission in 2019 update of the EULAR recommendations for the management of systemic lupus erythematosus' by Rua- Figueroa and Erausquin}

We thank Drs Rua-Figueroa and Erausquin for their interest in our manuscript and their insightful comment regarding our definition of remission in Figure 1 of the 2019 update of the European League Against Rheumatism recommendations for the management of systemic lupus erythematosus (SLE). ${ }^{1} 2$ The authors claim that the definition of remission in Figure 1 (SLEDAI 0, only on hydroxychloroquine) is too stringent, as it may guide physicians towards intensification of therapy in patients with sole serological activity. Instead, they recommend total SLEDAI to be substituted by a 'clinical SLEDAI' $=0$.

We agree with the authors-and there is general agreementthat the presence of serological activity per se is not an indication for treatment modifications in SLE, ${ }^{3}$ despite the fact that these patients may be at increased risk for subsequent flare. ${ }^{4}$ While a universally accepted definition of remission is still pending, the figure attempted to illustrate the ideal target of treatment in a disease as complex as SLE. In this regard, complete remission (clinical and serological) off-therapy constitutes the optimal target, as it minimises the risk for flare in any given patient. Nevertheless, we acknowledge that this condition represents a far-fetched goal for many patients in routine clinical practice. As the authors point out, several observational studies have shown comparable rates of damage accrual between remission and a low disease activity state. ${ }^{5}$ For this reason, a state of low disease activity is currently considered an acceptable alternative target, and this has been included in the figure. A serologically active, clinically quiescent patient on stable low-dose glucocorticoid therapy with or without immunosuppressants would usually fit into this definition, and thus, therapy intensification would not be advocated by the recommendations. This said, we believe that defining "remission as "clinical" SLEDAI- $2 \mathrm{~K}=0$ and, perhaps, a dose of prednisone no more than $5 \mathrm{mg} /$ day for patients with/without stable immunosuppressants and antimalarials' is probably a lenient definition and may not correspond to a true remission, rather to a low disease activity state (especially if immunosuppressants are needed to maintain it). In any case, both conditions are currently considered acceptable treatment targets for patients with lupus.

Antonis Fanouriakis, ${ }^{\oplus 1}$ George Bertsias, $^{2,3}$ Dimitrios T Boumpas ${ }^{\oplus 1,4,5}$
${ }^{1}$ Rheumatology and Clinical Immunology, 4th Department of Internal Medicine, "Attikon" University Hospital, Athens, Greece

${ }^{2}$ Department of Rheumatology, Clinical Immunology and Allergy, University Hospital of Heraklion, Heraklion, Greece

${ }^{3}$ Laboratory of Autoimmunity-Inflammation, Institute of Molecular Biology and Biotechnology, Heraklion, Greece

${ }^{4}$ Laboratory of Autoimmunity and Inflammation, Biomedical Research Foundation of the Academy of Athens, Athens, Greece

${ }^{5}$ Joint Academic Rheumatology Program, Medical School, National and Kapodestrian University of Athens, Athens, Greece

Correspondence to Dr Dimitrios T Boumpas, Medicine, National and Kapodestrian University of Athens, Athens 157 72, Greece; boumpasd@uoc.gr

Handling editor Josef S Smolen

Funding The authors have not declared a specific grant for this research from any funding agency in the public, commercial or not-for-profit sectors.

Competing interests None declared.

Patient consent for publication Not required.

Provenance and peer review Commissioned; internally peer reviewed.

(c) Author(s) (or their employer(s)) 2019. No commercial re-use. See rights and permissions. Published by BMJ.

\section{Check for updates}

To cite Fanouriakis A, Bertsias G, Boumpas DT. Ann Rheum Dis Epub ahead of print: [please include Day Month Year]. doi:10.1136/annrheumdis-2019-215810

Received 6 June 2019

Accepted 6 June 2019

\section{Linked}

- http://dx.doi.org/10.1136/annrheumdis-2019-215778

Ann Rheum Dis 2019;0:1. doi:10.1136/annrheumdis-2019-215810

\section{REFERENCES}

1 Rua Figueroa Îñigo, Erausquin C. Concerns about the operational definition of remission in 2019 update of the EULAR recommendations for the management of systemic lupus erythematosus. Ann Rheum Dis 2019.

2 Fanouriakis A, Kostopoulou M, Alunno A, et al. 2019 update of the EULAR recommendations for the management of systemic lupus erythematosus. Ann Rheum Dis 2019.

3 Steiman AJ, Gladman DD, Ibañez D, et al. Outcomes in patients with systemic lupus erythematosus with and without a prolonged serologically active clinically quiescent period. Arthritis Care Res 2012;64:511-8.

4 Steiman AJ, Gladman DD, Ibañez D, et al. Prolonged serologically active clinically quiescent systemic lupus erythematosus: frequency and outcome. J Rheumatol 2010;37:1822-7.

5 Zen M, laccarino L, Gatto M, et al. Lupus low disease activity state is associated with a decrease in damage progression in Caucasian patients with SLE, but overlaps with remission. Ann Rheum Dis 2018;77:104-10.

6 Petri M, Magder LS. Comparison of remission and lupus low disease activity state in damage prevention in a United States systemic lupus erythematosus cohort. Arthritis Rheumatol 2018;70:1790-5. 